\title{
INFLUÊNCIA DA ÉPOCA DE EXTRAÇÃO NA QUALIDADE FISIOLÓGICA DE SEMENTES DE PORONGO
}

\author{
INFLUENCE OF EXTRACTION TIME ON THE PHYSIOLOGICAL \\ QUALITY OF BOTTLE GOURD SEEDS
}

\author{
Dilson Antônio Bisognin ${ }^{1}$ Nilson Lemos de Menezes ${ }^{2}$ \\ Ricardo Centenaro ${ }^{3}$ Adriana Maia Albini ${ }^{4}$
}

RESUMO

Um experimento foi conduzido em campo e em laboratório com o objetivo de determinar a melhor época de extração, visando à obtenção de sementes de porongo de alta qualidade fisiológica. As épocas de extração das sementes foram as seguintes: na maturidade dos frutos, na senescência das plantas e 30, 60 e 90 dias após. Foram avaliados a germinação e o vigor no momento da extração e em períodos de 30 dias até 120 dias do início do armazenamento das sementes. A colheita por ocasião da senescência natural das plantas, seguida de armazenamento dos frutos à sombra, por um período de 49 e 57 dias, proporcionou a maior germinação e vigor, respectivamente, no momento da extração do fruto, sendo que o máximo peso de 1000 sementes ocorreu aos 56 dias, com 193,5g. O armazenamento das sementes no fruto esteve associado à melhoria da qualidade fisiológica das sementes por ocasião da extração, enquanto que em laboratório eliminou a dormência e aumentou a velocidade de germinação. A colheita dos frutos de porongo visando à extração das sementes deve ser realizada por ocasião da senescência das plantas; a manutenção das sementes dentro de fruto maduro aumenta a germinação e o vigor; o armazenamento dos frutos, por 56 dias, resulta na obtenção de sementes de alta qualidade fisiológica.

Palavras-chave: germinação, vigor, Lagenaria siceraria.

\section{SUMMARY}

An experiment was carried out in laboratory in order to determinate the best extraction time for obtaining high physiological quality of bottle gourd seeds. The seed extraction times were: fruit maturity period, plant scenescency and after 30, 60 and 90 days of fruit storage. The evaluation of seed germination and vigor was done at the extraction and every 30 days until 120 days after the beginning of the experiment. Fruits harvested at the natural death of the plants and shade stored for 49 and 57 days resulted in the highest germination and vigor, respectively, at the extraction epoch. That treatment showed the highest weight of 1000 seeds of $193.5 \mathrm{~g}$ at 56 days. The storage of the seeds in the fruit was associated with the improvement of the seed physiological quality at extraction epoch. On the other hand, the laboratory storage of the seeds was associated to the dormancy breaking and the germination period shortening. In conclusion, the fruits of bottle gourd to extract seeds must be harvested at the natural death of the plants. Keeping seeds inside de fruits increases their germination and vigor. The shade storage of the fruits for 56 days produce high physiological quality in bottle gourd seeds.

Key words: germination, vigor, Lagenaria siceraria.

\section{INTRODUÇÃO}

O porongo - Lagenaria siceraria (Mol.) Standl -, planta da família das cucurbitáceas, apesar de sua grande importância para os pequenos produtores do Rio Grande do Sul, principalmente da região de Santa Maria, muito pouco se conhece em relação ao seu manejo e produção de sementes. As diferentes populações de plantas existentes na Região são semelhantes em seu desenvolvimento, sendo que a diferença de rendimento existente está relacionada com o maior porcentual de frutos industrializáveis (BISOGNIN \& MARCHEZAN, 1988), ou seja, aqueles produtores que fazem seleção de frutos para a extração das sementes detêm populações com

\footnotetext{
${ }^{1}$ Engenheiro Agrônomo, Mestre, Professor do Departamento de Fitotecnia, Universidade Federal de Santa Maria (UFSM), Campus Universitário.

${ }^{2}$ Engenheiro Agrônomo, Doutor, Professor do Departamento de Fitotecnia, UFSM, Camobi, 97119-900, Santa Maria, RS E-mail: nmenezes@ccr.ufsm.br. Autor para correspondência.

${ }^{3}$ Acadêmico do Curso de Agronomia, Bolsista do Programa Institucional de Bolsas de Iniciação Científica (PIBIC) do CNPq/UFSM.

${ }^{4}$ Engenheiro Agrônomo, ex-aluna do Curso de Agronomia, UFSM.
} 
maior freqüiência de genes que conferem à produção de frutos um formato mais adequado para a indústria de cuia.

Esta espécie apresenta crescimento indeterminado, o que acarreta uma grande desuniformidade nos estádios de maturidade dos frutos, podendo se refletir no tamanho dos mesmos e na qualidade fisiológica das sementes (BISOGNIN et al., 1997). A produção de frutos menores pode ser decorrente do uso de alta densidade (BISOGNIN et al., 1992) ou devido à senescência natural das plantas, que interrompe o crescimento do fruto (BISOGNIN et al., 1997), podendo apresentar sementes imaturas e de menor qualidade fisiológica.

A colheita de frutos para fins de extração das sementes em cucurbitáceas é feita normalmente quando os frutos estão maduros, porém, pode ser realizada até mesmo antes do completo amadurecimento, seguido de armazenamento pós-colheita (LOPES \& CASALI, 1982). Assim sendo, é de fundamental importância a determinação do ponto ideal de colheita dos frutos combinado ao armazenamento pós-colheita para a obtenção de sementes de alta qualidade fisiológica. $\mathrm{O}$ armazenamento póscolheita dos frutos está relacionado ao fato de que as sementes continuam seu amadurecimento, caso não o tenham completado no campo, atingindo níveis máximos de germinação e vigor (ARAÚJO $\boldsymbol{e t} \boldsymbol{a l}$, 1982; ALVARENGA et al., 1984; PEDROSA et al., 1987; ALVARENGA et al., 1991; BARBEDO et al., 1994).

Os resultados de pesquisas realizadas com outras cucurbitáceas indicam comportamentos variados em relação à época ideal de colheita e ao tempo de armazenamento pós-colheita. Os resultados mais positivos na germinação e no vigor foram obtidos quando a colheita dos frutos foi efetuada precocemente em abóbora (ARAÚJO et $\boldsymbol{a l}$., 1982), em abobrinha italiana (ALVARENGA et al., 1991) e, também, em pepino (BARBEDO et al., 1994). Efeitos negativos sobre a qualidade das sementes foram observados quando a colheita tardia foi efetuada em melancia, devido à possível deterioração dos frutos (ALVARENGA et al., 1984). Esse momento de colheita, entretanto, não modificou a qualidade das sementes de pepino (BARBEDO et al., 1994). Assim, este trabalho teve como objetivo determinar a melhor época de extração visando à obtenção de sementes de porongo de alta qualidade fisiológica.

\section{MATERIAL E MÉTODOS}

Os frutos utilizados neste experimento provieram de uma lavoura localizada no município de Restinga Seca, RS. A semeadura foi realizada no dia 18/09/94, na densidade de 13.300 plantas/ha e a adubação foi de 7,5, 30 e $30 \mathrm{~kg} /$ ha de $\mathrm{N}, \mathrm{P}_{2} \mathrm{O}_{5}$ e $\mathrm{K}_{2} \mathrm{O}$, respectivamente. A colheita dos frutos foi realizada em duas épocas: por ocasião do seu amadurecimento e 30 dias após, na senescência das plantas, momento em que normalmente é efetuada pelo produtores. Os frutos colhidos das plantas senescentes foram armazenados à sombra para a extração das sementes em diferentes períodos. As épocas de extração das sementes foram as seguintes: na maturidade dos frutos, na senescência das plantas, e 30, 60 e 90 dias após a senescência das plantas.

O grau de umidade das sementes foi determinado pelo método de estufa, com temperatura de $105{ }^{\circ} \mathrm{C} \pm 3^{\circ} \mathrm{C}$. Para o peso de 1000 sementes, utilizaram-se oito repetições, obtidas da porção de sementes puras. Ambas determinações foram executadas conforme indicam as Regras para Análise de Sementes (BRASIL, 1992). A qualidade fisiológica foi avaliada por meio do teste de germinação, conforme metodologia descrita por BISOGNIN et al. (1991) e pelos testes de vigor: primeira contagem de germinação ( $4^{\circ}$ dia) e tempo médio de germinação (TMG), em quatro repetições de 50 sementes. Foram consideradas sementes não germinadas aquelas mortas ou dormentes, aos 14 dias do início do teste de germinação. O TMG foi calculado através da fórmula proposta por HARRINGTON (1972), sendo:

$$
\mathrm{TMG}=\left(\mathrm{N}_{1} \mathrm{~T}_{1}+\mathrm{N}_{2} \mathrm{~T}_{2}+\ldots+\mathrm{N}_{\mathrm{n}} \mathrm{T}_{\mathrm{n}}\right) /\left(\mathrm{N}_{1}+\mathrm{N}_{2}+\ldots+\mathrm{N}_{\mathrm{n}}\right)
$$

onde: $\mathrm{N}$ é o número de sementes germinadas e $\mathrm{T}$ é o tempo em dias.

Estes testes foram realizados em sementes recém extraídas e a cada 30 dias, até que as sementes extraídas de fruto maduro completaram armazenamento em laboratório de 120 dias. Desse modo, as sementes, após extraídas dos frutos, foram secadas ao ar e armazenadas em laboratório, com exceção daquelas extraídas aos 90 dias após a senescência das plantas, que foram avaliadas apenas por ocasião da extração, caracterizando dois tipos de armazenamento, no fruto e/ou no laboratório.

Os dados de época de extração das sementes do fruto e de armazenamento em laboratório e das combinações de armazenamento em laboratório e/ou no fruto foram analisados conforme o delineamento inteiramente casualizado. Os efeitos dos tratamentos foram estudados por regressão polinomial, sendo o tempo igual a zero correspondente à extração de sementes de frutos maduros no dia em que foram colhidos. Para efeito de análise estatística, os dados de primeira contagem e de germinação foram transformados para arco seno. 


\section{RESULTADOS E DISCUSSÃO}

A manutenção das sementes de porongo dentro do fruto favoreceu a obtenção de maior germinação e vigor, o qual foi medido pela primeira contagem e pelo tempo médio de germinação (TMG). A maior porcentagem de germinação foi obtida aos 79 dias, com um aumento de $73,3 \%$ sobre a porcentagem obtida no momento da extração das sementes de fruto maduro (Figura 1). Também, a menor porcentagem de sementes não germinadas foi obtida aos 78 dias, após a primeira extração. $\mathrm{O}$ menor TMG foi obtido aos 87 dias, após o amadurecimento do fruto, com um índice de 2,6 dias, o que corresponde a um aumento no vigor na ordem de $76,4 \%$.

Considerando que a partir do amadurecimento dos frutos são necessários, aproximadamente, 30 dias para a senescência natural das plantas, momento em que os produtores executam a colheita, constatou-se que os frutos devem ser colhidos e armazenados à sombra por um período de 49 e 57 dias, antes da extração das sementes, para a obtenção de maior germinação e vigor, respectivamente. Esses resultados mostram que em porongo ocorre um fluxo de nutrientes do fruto para as sementes após a sua colheita, a exemplo do que ocorre em outras cucurbitáceas como a abóbora (ARAÚJO et al., 1982), melancia (ALVARENGA $\boldsymbol{e t}$ al., 1984), abobrinha italiana (ALVARENGA et al., 1991), pepino (BARBEDO et al. 1994) e em sementes híbridas de Cucurbita maxima x C. moschata (PEDROSA et al., 1987), em que os máximos valores de germinação e vigor foram obtidos após certo período de armazenamento pós-colheita dos frutos, antes da extração das sementes.

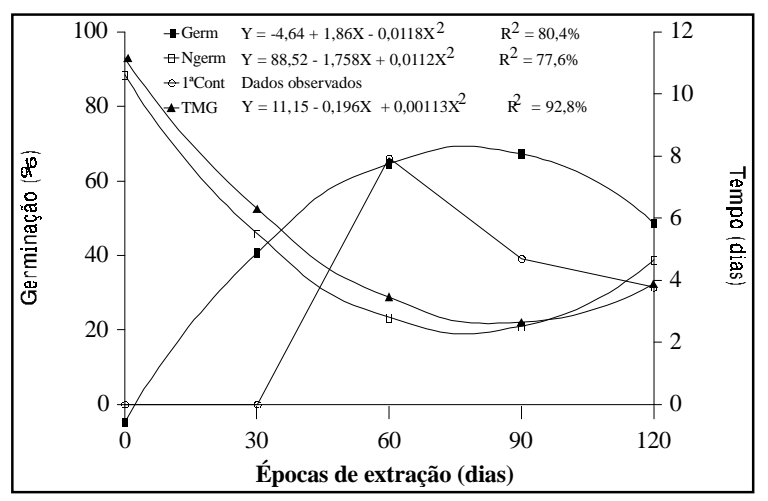

Figura 1 - Porcentagem de germinação (Germ), de sementes não germinadas (Ngerm) e vigor $\left(1^{\text {a }}\right.$ contagem de germinação e tempo médio de germinação - TMG) de sementes de porongo para diferentes momentos da extração do fruto. Santa Maria, RS, 1997.
A permanência das sementes dentro do fruto resultou em aumento significativo do peso de 1000 sementes, sendo que o máximo peso foi obtido aos 86 dias depois da maturidade do fruto, ou 56 dias após a senescência das plantas, com 193,5g (Figura 2), que, praticamente, coincidiu com o maior vigor das sementes obtido pelo menor TMG aos 57 dias. O teor de água das sementes no momento da sua extração do fruto mostra que ocorreu uma drástica redução a partir de 30 dias de armazenamento dos frutos à sombra. Independente do grau de umidade inicial das sementes, a secagem ao ar proporcionou redução do mesmo, estabilizando-o em aproximadamente $10 \%$, o que é favorável para a manutenção da qualidade fisiológica, durante o armazenamento. $\mathrm{O}$ grau de umidade e o aumento do peso de 1000 sementes são indicativos de que a maturidade fisiológica das mesmas ocorreu após a mudança da coloração do fruto, pois, à medida que a semente se desenvolve, aumenta seu peso, tanto de massa fresca, como de massa seca, até atingir um máximo, quando as sementes, normalmente, atingem o máximo vigor e germinação (POPINIGIS, 1977). Tal fato justifica o aumento da qualidade fisiológica das sementes pela permanência do fruto à sombra. Assim sendo, o melhor momento para a extração das sementes ocorreu aos 56 dias, após a senescência das plantas, justificando o fato da melhoria da qualidade fisiológica das sementes pela permanência do fruto aderido à planta e, também, pelo armazenamento do fruto à sombra. O aumento do peso de 1000 sementes é explicado pelo fluxo de nutrientes do fruto para a semente, como consequiência da permanência na planta ou do armazenamento pós-colheita, verificado em melancia por ALVARENGA et al. (1984).

$\mathrm{O}$ armazenamento das sementes em laboratório, após a sua extração de frutos maduros, proporcionou um aumento da porcentagem de germinação até 84 dias, com uma porcentagem obtida de

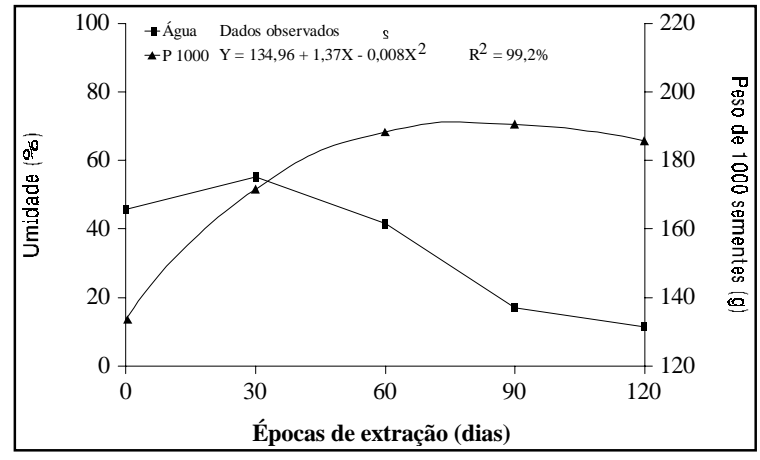

Figura 2 - Umidade e peso de 1000 sementes de porongo para diferentes momentos da extração do fruto. Santa Maria, RS, 1997.

Ciência Rural, v. 29, n. 1, 1999. 
$46,6 \%$ e do vigor, avaliado pela primeira contagem, 103 dias, equivalente a 32,7\% (Figura 3A). A menor porcentagem de sementes não germinadas foi obtida aos 86 dias, sendo que o vigor, avaliado através do TMG, aumentou de forma linear pelo tempo de armazenamento das sementes em laboratório. Esses resultados mostram que o armazenamento das sementes em laboratório não resulta em um aumento da qualidade fisiológica das sementes, equivalente ao armazenamento no fruto, confirmando que as sementes, após a maturidade do fruto, ainda dependem deste para complementar o seu desenvolvimento e chegar à maturidade fisiológica, detectada pelo aumento da germinação e do vigor. Também, a maturidade do fruto ocorreu quando as sementes ainda não haviam atingido a máxima germinação e vigor, pois o seu armazenamento em laboratório, que possibilitaria a eliminação da dormência, não se equivaleu à qualidade fisiológica atingida pela permanência das sementes dentro do fruto e este preso à planta até a sua senescência.

A extração das sementes de frutos colhidos por ocasião da senescência natural das plantas,

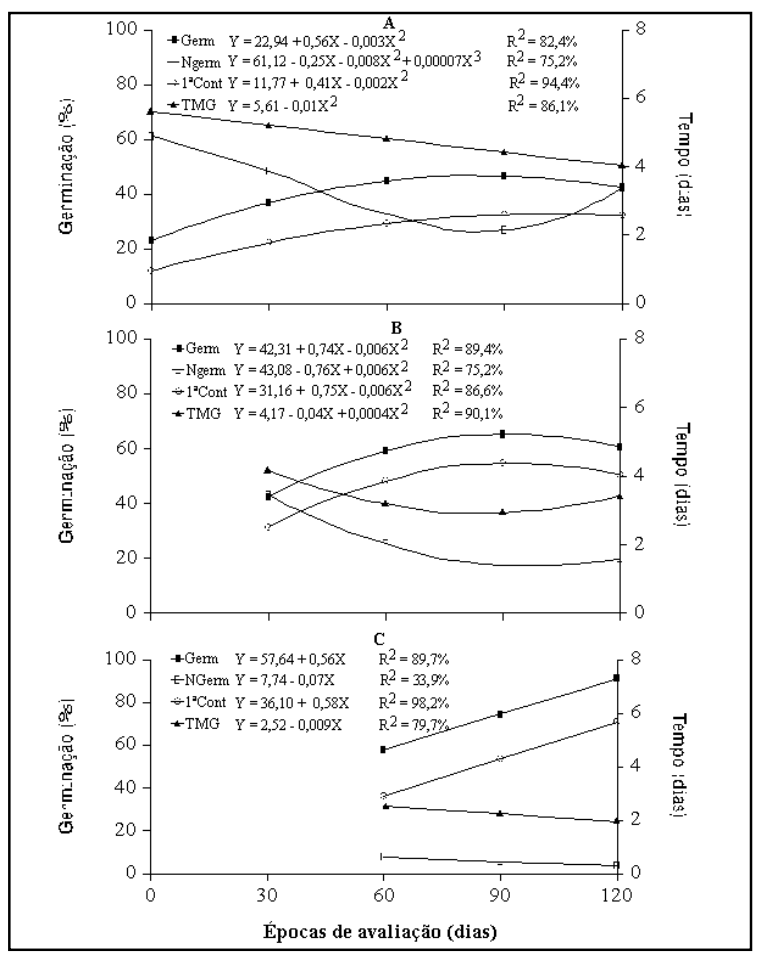

Figura 3 - Porcentagem de germinação (Germ), de sementes não germinadas (Ngerm) e vigor $\left(1^{\mathrm{a}}\right.$ contagem de germinação e tempo médio de germinação - TMG) de sementes de porongo extraídas de frutos maduros (A), na senescência das plantas (B), seguido de armazenamento à sombra por 30 dias (C) e armazenadas em laboratório por diferentes períodos. Santa Maria, RS, 1997. seguida de armazenamento em laboratório, proporcionou um aumento da germinação e do vigor em relação à extração das sementes de fruto maduro (Figura 3B). A permanência do fruto na planta até a sua senescência promoveu um aumento da germinação da ordem de $45,8 \%$ e do vigor de $62,2 \%$, pela primeira contagem, e de $25,7 \%$, pelo TMG, indicando que os frutos devem ser colhidos nessa época. A maior germinação ocorreu aos 61,9 dias de armazenamento em laboratório, com uma porcentagem obtida de $65,2 \%$. O maior vigor, obtido pela $1^{\mathrm{a}}$ contagem, foi obtido aos 63 dias, com 54,7\% de plântulas normais, e pelo TMG aos 55 dias, com um TMG de 2,93 dias.

As sementes extraídas dos frutos colhidos na senescência das plantas e armazenadas por 30 dias também aumentaram a germinação e o vigor, quando comparadas com as da extração logo após a colheita (Figura 3C), mostrando novamente que os frutos de porongo, após colhidos, devem ser armazenados à sombra antes da extração das sementes. $\mathrm{O}$ armazenamento, em laboratório, por 60 dias, promoveu um aumento de $36,2 \%$ na germinação e $49,1 \%$ no número de plântulas normais, aos quatro dias do início do teste de germinação e uma redução de $54,3 \%$ na porcentagem de sementes não germinadas e de $21,4 \%$ no TMG. A melhoria da germinação e do vigor das sementes resultantes do armazenamento pós-colheita é devido à eliminação da dormência, pois nos primeiros 30 dias, após a colheita, as sementes de cucurbitáceas podem apresentar dormência ou germinação muito lenta (CASALI et al., 1982).

O armazenamento das sementes extraídas de frutos colhidos quando as plantas estavam senescentes, seguido de armazenamento à sombra, por 60 dias, proporcionou um aumento significativo da germinação e do número de plântulas normais, aos quatro dias, e uma redução da porcentagem de sementes não germinadas, porém não afetou o TMG. Isso confirma que o armazenamento, após a extração, foi eficaz na eliminação de dormência das sementes e, mesmo por apenas 30 dias, aumentou a velocidade de germinação pela maior porcentagem de plântulas normais germinadas até o quarto dia, apesar do TMG não detectar essa melhoria do vigor.

A combinação de armazenamento dos frutos previamente à extração das sementes, seguido de armazenamento em laboratório, proporcionou a melhor qualidade fisiológica das sementes de porongo (Figura 4). Em termos de porcentagem de germinação, o máximo poder germinativo foi obtido na extração das sementes aos 58 dias, com 82,8\% de plântulas normais e a menor porcentagem de sementes não germinadas aos 62 dias, com apenas 


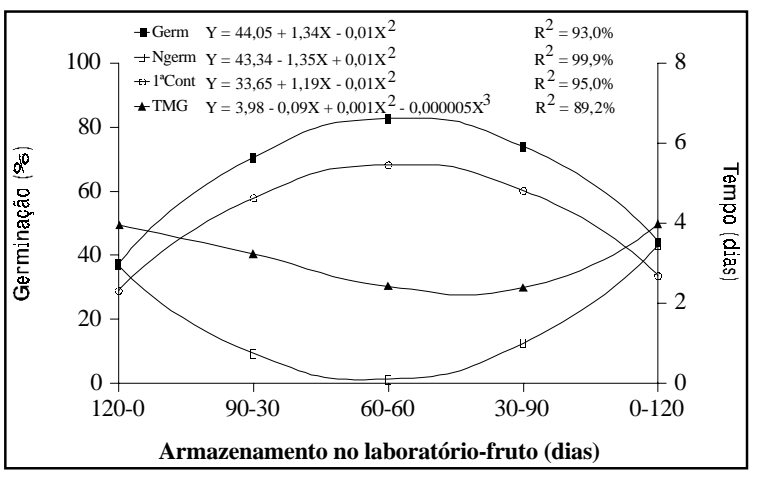

Figura 4 - Porcentagem de germinação (Germ), de sementes não germinadas (Ngerm) e vigor $\left(1^{\mathrm{a}}\right.$ contagem de germinação e tempo médio de germinação - TMG) de sementes de porongo armazenadas em laboratório e/ou no fruto por diferentes períodos aos 120 dias do início do experimento. Santa Maria, RS, 1997.

$1,2 \%$ de sementes não germinadas. Em relação ao vigor, a maior porcentagem de plântulas normais no quarto dia ( $1^{\mathrm{a}}$ contagem) foi obtida na extração das sementes aos 58 dias, com 68,2\% e o menor TMG aos 77, dias com um índice de 2,3 dias. Esses resultados se justificam pela eliminação antecipada da dormência, que ocorre ao longo do armazenamento, conforme mostra a Figura 3.

A melhoria da qualidade fisiológica das sementes de porongo obtida com a combinação do armazenamento das sementes no fruto e no laboratório comparada com a qualidade no momento da extração (Figura 1) se deve à interação positiva que ocorre entre os dois tipos de armazenamento. O armazenamento das sementes no fruto esteve associado à melhoria da qualidade fisiológica das sementes por ocasião da extração, e o armazenamento em laboratório, com a eliminação da dormência e com o aumento da velocidade de germinação. Ganhos na qualidade fisiológica também podem ser obtidos com a fermentação logo após a extração das sementes, conforme observado por BISOGNIN et al. (1997).

Um aspecto que ainda deve ser ressaltado é que o efeito do armazenamento do fruto póscolheita sobre a qualidade fisiológica das sementes apresenta grandes variações entre espécies de cucurbitáceas com determinadas características de fruto. BARBEDO et al. (1994) determinaram duas épocas de colheita em pepino: precoce (quando os frutos apresentavam coloração externa transitória do verde ao amarelo-esbranquiçado) associado ao armazenamento de 15 dias, ou tardia (frutos com coloração externa amarelo-claro) e imediata extração das sementes. Por outro lado, colheita tardia (realizada aos 75 dias após a antese) associada ao armazenamento por 45 dias é que resultou na melhor qualidade fisiológica das sementes híbridas de Cucurbita maxima x C. moschata (PEDROSA et al., 1987), semelhante aos resultados obtidos neste experimento. $\mathrm{O}$ fato de que o armazenamento pós-colheita em melancia e pepino não tenha sido benéfico à qualidade fisiológica das sementes poderia ser esperado, pois os frutos destas espécies apresentam uma rápida deterioração, sendo necessária a retirada de suas sementes. Em espécies em que o fruto pode manter-se em condições de ambiente não controlado por vários anos, como é o caso do porongo ou da moranga, de relativo longo período de conservação pós-colheita, há a possibilidade de se associar os benefícios da manutenção das sementes dentro do fruto, obtendo sementes de alta qualidade fisiológica já na extração, com os benefícios do armazenamento ou do método de extração, para a obtenção de sementes de alta qualidade fisiológica, capazes de proporcionar uma implantação rápida e uniforme das plântulas no campo, necessárias para a obtenção de altos rendimentos.

\section{CONCLUSÕES}

A colheita dos frutos de porongo visando à extração das sementes deve ser realizada por ocasião da senescência das plantas; a manutenção das sementes dentro de fruto maduro aumenta a germinação e o vigor; o armazenamento dos frutos à sombra por 56 dias resulta na obtenção de sementes de alta qualidade fisiológica.

\section{REFERÊNCIAS BIBLIOGRÁFICAS}

ALVARENGA, E.M., SILVA, R.F. ARAÚJO, E.F., $\boldsymbol{e} t \boldsymbol{a l}$. Influência da idade e armazenamento pós-colheita dos frutos na qualidade de sementes de melancia. Horticultura Brasileira, Brasília, v. 2, n. 2, p. 5-8, 1984.

ALVARENGA, E.M., SILVA, R.F., ARAÚJO, E.F., $\boldsymbol{e} t \boldsymbol{a l}$. Maturação fisiológica de sementes de abóbora italiana. Revista Brasileira de Sementes, Brasília, v. 11, n. 2, p. $147-$ $150,1991$.

ARAUJO, E.F., MANTOVANI, E.C., SILVA, R.F. da. Influência da idade $\mathrm{e}$ armazenamento dos frutos na qualidade de sementes de abóbora. Revista Brasileira de Sementes, Brasília, v. 4, n. 4, p. 77-87, 1982.

BARBEDO, C.J., NAKAGAWA, J., BARBEDO, A. S.C. $\boldsymbol{e} \boldsymbol{t} \boldsymbol{a}$. Influência da idade e do período de repouso pós-colheita de frutos de pepino cv. Rubi na qualidade fisiológica de sementes. Horticultura Brasileira, Brasília, v. 12, n. 2, p. 118-124, 1994.

BISOGNIN, D.A., IRIGON, D.L., MARTINAZZO, A.A. Teste de germinação em porongo - Lagenaria siceraria (Mol. ) Standl. Ciência Rural, Santa Maria, v. 21, n. 2, p. 159-167, 1991. 
BISOGNIN, D.A., MARCHESAN, E. Avaliação de algumas populações de porongo - Lagenaria siceraria (Mol.) Standl. cultivadas na região de Santa Maria, RS. Revista do Centro de Ciências Rurais, Santa Maria, v. 18, n. 3-4, p. 201-207, 1988.

BISOGNIN, D.A., MARCHESAN, E., AUDE, M.I. da S. Densidade de semeadura e produtividade do porongo. Ciência Rural, Santa Maria, v. 22, n. 1, p. 15-19, 1992.

BISOGNIN, D.A., MENEZES, N.L. de, BELLÉ, R.A., $\boldsymbol{e} \boldsymbol{t} \boldsymbol{a l}$ Efeito do tamanho de fruto e do método de extração na qualidade fisiológica de sementes de porongo. Ciência Rural, Santa Maria, v. 27, n. 1, p. 13-19, 1997.

BRASIL. Ministério da Agricultura e Reforma Agrária, Departamento Nacional de Produção Vegetal. Divisão de Sementes e Mudas. Regras para Análise de Sementes. Brasília: Ministério da Agricultura, 1992, 365 p.
CASALI, V.W.D., SATURNINO, H.M., PEDROSA, J.F. Botânica e origem das cucurbitáceas. In: EPAMIG. As cucurbitáceas. Informe Agropecuário, Belo Horizonte, v. 8, n. 85 , p. $22-23,1982$.

HARRINGTON, J.F. Seed Storage Longevity. In: KOZLOSKI, T. T. Seed Biology. New York: Academic Press, 1972. v. 3. p. 145-245.

LOPES, J.F., CASALI, V.W.D. Produção de sementes de cucurbitáceas. In: EPAMIG. As cucurbitáceas. Informe Agropecuário, Belo Horizonte, v. 8, n. 85, p. 65-67, 1982.

PEDROSA, J.F., OLIVEIRA, G.M., BEZERRA NETO, F., et al. Influência da idade e armazenamento do fruto na produção e qualidade de sementes de Cucurbita maxima x C. moschata. Horticultura Brasileira, Brasília, v. 5, n. 2, p. 15-17, 1987.

POPINIGIS, F. Fisiologia da semente. Brasília: AGIPLAN, 1977. $289 \mathrm{p}$

Ciência Rural, v. 29, n. 1, 1999. 